Transport and Communications Science Journal

\title{
AN EXPERIMENTAL STUDY ON PRODUCTION OF HIGH STRENGTH NON-SHRINK GROUT CONTAINING FLY ASH
}

\author{
Dang Thuy Chi
}

University of Transport and Communications, No 3 Cau Giay Street, Hanoi, Vietnam

ARTICLE INFO

TYPE: Research Article

Received: 14/04/2021

Revised: 21/05/2021

Accepted: 24/05/2021

Published online: 27/05/2021

https://doi.org/10.47869/tcsj.72.4.7

${ }^{*}$ Corresponding author

Email: thuychi.dang@utc.edu.vn

\begin{abstract}
Cement-based grouts are widely used thanks to its outstanding features such as high workability, non-separation, non-bleeding, easy to fulfill small gaps with complex shapes. This paper descrcibes the first phase of a series of laboratory experiments that examined the ability of production of self - levelling mortar at the University of Transport and Communications. The Portland cement-based grout incorporated superplasticizer, fly ash, fine aggregate, water along with expansion agent to match as closed as possible the given high strength non-shrink grout. The experimental study focused on the performance of non-shrink grouts regarding the flowability, expansion and bleeding, strengths and drying shrinkage of the test grout mixtures. The high range water reducer (HRWR) at dosage of $1 \%$ by weight of cement was used as a flowability modifying chemical admixture to prevent water segregation and leads to an increase in compressive strength. The parameter tests consist of water-cement ratios, and fixed dosages of superplasticizer and expansive agent. To examine the flowability of grout mortars, the flow cone test was applied. The flow cone test result indicated that there were three proportional of grouts that can meet the requirement of fluidity. The compressive strength of specimens was tested according to ASTM C349-14. It was concluded that the compositions of grouts at a water-cement ratio of from 0.29 to 0.33 have compressive strengths greater than $60 \mathrm{MPa}$. The tested specimens using the expansive agent with the dosage recommended by the manufacturer meet the non-shrinkage requirement of a grout. The experimental results have demonstrated the ability of production of high strength non-shrink grouts.
\end{abstract}

Keywords: Non-shrink, high compressive strength, grout, self - levelling 


\section{INTRODUCTION}

The search for the advanced materials is one of the active areas of research in all the disciplines of engineering and science. Similarly, the extensive efforts have been made in the construction industry to produce high performance materials such as grouts. Grouts are very commonly used in construction thank to its outstanding features such as high workability, non-separation, non-bleeding, easy to fulfill small gaps with complex shapes, as well as cover such features as high compressive strength, high impact resistance, and so on.

Grout is made on the basis of cement base combining with mineral additives, chemical adjuvants and expansion agent, often mixed in the factory, convenient for construction and quality assurance at work. Compared with conventional cement mortars, pre-mixed selflevelling mortars have higher quality and more applications. However, due to cost reasons, self-flowing mortar is only used for such assignments as machine foundation, pile-head locking concrete, repairing concrete, bridge decks, bearings, bridge joints, positions subjected to impacts, and so on.

Choosing an appropriate grout mixture is entirely dependent on the project and its necessities. Some projects are only done for sealing of the ground. Therefore, the strength of the grout is not much considered in mix design. In some other projects, on the other hand, strengthening the ground may be the main purpose of grouting Azadia et al [1]. Moreover, bleeding and drying shrinkage are the characteristics that should be minimized all the time.

In recent years, the grout is widely used in Vietnam. Several mortars were proportioned to meet the requirements for field activities at sites with various materials. The majority of these grout mixtures used proportionally large volumes of either Portland cement or silica fume (or both) to achieve needed high compressive strength requirements [2]. Therefore, the cost of these grouts is quite high. Moreover, other grout mixtures also used specific materials such as polypropylene fiber or polymer acrcylic to achieve the high properties of $[2,3]$. Those materials will complicate the construction process as well as reduce the flowability of the grout.

The purpose of this research is to use the proactive available materials such as fly ash, superplasticizer and expansive agent making possibility of the resultant grout mixture exhibiting the high performance. This paper presents the results on fabrication of non-shrink grouts which achieve the high compressive strength up to more than $60 \mathrm{MPa}$ without using silica fume or special materials.

\section{MATERIALS AND EXPERIMENTAL METHODS}

\subsection{Materials and mixture proportions}

A PC40 portland cement (according to the standard TCVN 2682-2009) has been used for the grouts (table 1).

The sand used in this study is the Lo river one. Its characteristics and grading have been tested complying with ASTM C33-08 [4] (figure 1).

The mineral admixture used in the research was a type-F fly ash complying with the TCVN 10302:2014. The mineral additive plays a role of filling the porosity and improving the consistency of the grout. The chemical composition of used fly is shown in Table 2. 
Transport and Communications Science Journal, Vol. 72, Issue 4 (05/2021), 477-485

Table 1. Used cement properties in comparaison with TCVN 2682-2009 requirements.

\begin{tabular}{|c|c|c|}
\hline Properties & Value & $\begin{array}{c}\text { Requirement according to } \\
\text { TCVN 2682-2009 }\end{array}$ \\
\hline \multicolumn{3}{|l|}{ Compressive strength (MPa) } \\
\hline At 3 days & 30 & $\geq 21$ \\
\hline At 28 days & 50 & $\geq 40$ \\
\hline \multicolumn{3}{|l|}{ Time of setting, min } \\
\hline Initial set & 110 & $\geq 45$ \\
\hline Final set & 200 & $\leq 375$ \\
\hline Finesse, Blaine method, $\mathrm{cm}^{2} / \mathrm{g}$ & 3518 & $\geq 2800$ \\
\hline Expansion, Le Chaterlier test, mm & 0.5 & $\leq 10$ \\
\hline $\mathrm{SO}_{3}$ content, $\%$ & 1.86 & $\leq 3.5$ \\
\hline
\end{tabular}

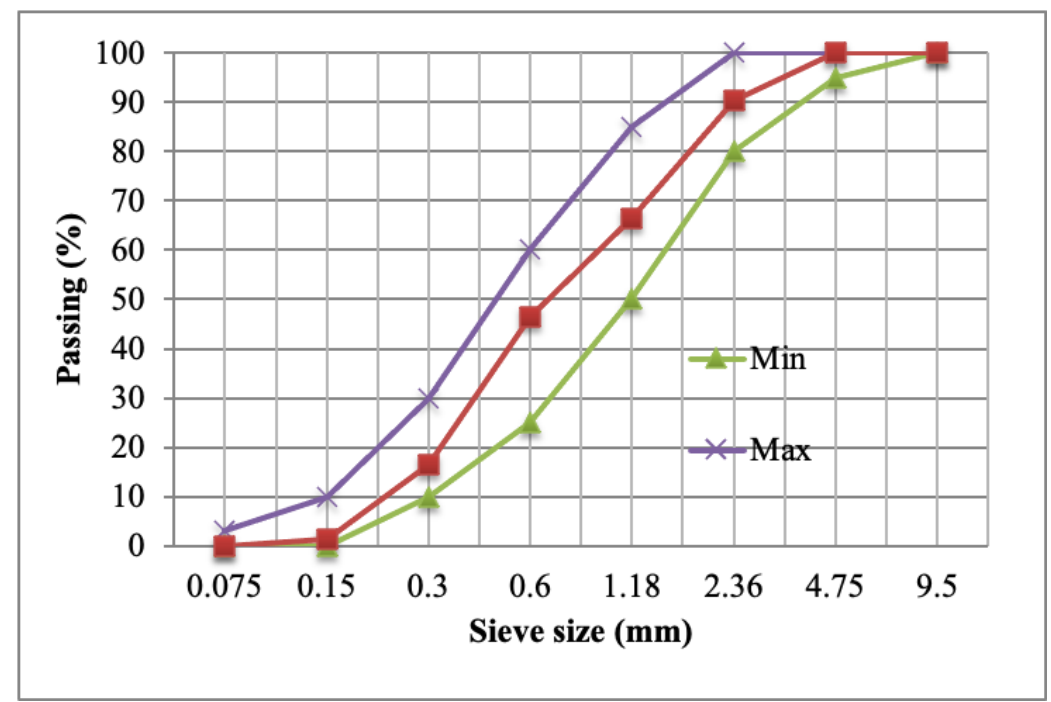

Figure 1. Grading curve of the sand used in the study.

Table 2. Chemical composition (wt.\%) of used fly ash.

\begin{tabular}{|l|c|c|c|c|c|c|c|c|c|}
\hline Oxides & $\mathrm{SiO}_{2}$ & $\mathrm{Al}_{2} \mathrm{O}_{3}$ & $\mathrm{Fe}_{2} \mathrm{O}_{3}$ & $\mathrm{CaO}$ & $\mathrm{MgO}$ & $\mathrm{Na}_{2} \mathrm{O}$ & $\mathrm{K}_{2} \mathrm{O}$ & $\mathrm{TiO}_{2}$ & LOI \\
\hline FA & 58.70 & 22.87 & 7.31 & 0.98 & 0.85 & 0.33 & 3.6 & 1.35 & 3.53 \\
\hline
\end{tabular}

The high range water reducer was a polycarboxylate powder, which allows improving and maintaining the flow ability of the grout.

An expansive agent based on CSA (calcium sulphoaluminate) was used for all the grout mixtures in order to emphasize the properties of the length-change by both increasing the initial expansion and reducing the subsequent drying shrinkage.

In this study, the constituent materials of grout mixtures were calculated by using the absolute volume method. The grout is considered to be completely dense and the total volume is equal to the sum of the constituent material ones.

The two basic and most important technical requirements used to mix design are: 
Transport and Communications Science Journal, Vol. 72, Issue 4 (05/2021), 477-485

- Flowability

- Compressive strength at 28 days.

Table 3 summarizes all the mixture proportioning in the study. The polycarxylate HRWR with a specific gravity of $1.1 \mathrm{~g} / \mathrm{cm}^{3}$ has been used with a proportion of $1 \%$ by cement weight. All grouts had been fixed the dosage of expansive agent at $10 \%$ by weight of cement, in accordance with the recommendation of the proceducer.

Table 3. Mixture proportions of Grout.

\begin{tabular}{|l|c|c|c|}
\hline \multicolumn{1}{|c|}{ Materials } & CT1 & CT2 & CT3 \\
\hline PC40 portland cement $(\mathrm{kg})$ & 500 & 550 & 615 \\
\hline Sand $(\mathrm{kg})$ & 1193 & 1193 & 1193 \\
\hline Fly ash $(\mathrm{kg})$ & 321 & 279 & 224 \\
\hline Water $(\mathrm{kg})$ & 195 & 195 & 195 \\
\hline Expansive agent $(\mathrm{kg})$ & 50 & 55 & 61,5 \\
\hline HRWR $(\mathrm{kg})$ & 5.0 & 5.75 & 6.15 \\
\hline W/B & 0.33 & 0.31 & 0.29 \\
\hline
\end{tabular}

\subsection{Experimental methods}

\section{- Mixing procedure}

The grout mixtures were mixed in a Hobart mixer (5 liters) at $140 \mathrm{rpm}$. The procedure consisted of adding all dry materials to the mixer and pre-mixing for 1 minutes. Afterwards, the water was added. The grout was further mixed for 2 minutes, allowed to rest for $30 \mathrm{~s}$, then mixed again for 2 minutes.

For the strength at early age, the specimens were demolded and tested after 1 day. After 24 hours, the other specimens are removed from their molds and stored in moist rooms at saturated humidity and temperature at $20 \pm 2{ }^{\circ} \mathrm{C}$ until 28 days.

\section{- Experimental methods}

Experimental properties and test methods are shown in Table 4.

The flow of the fresh grout is the resulting increase in average base diameter of the mortar mass, expressed as a percentage of the original base diameter.

Table 4. Experimental properties and test methods.

\begin{tabular}{|c|l|c|}
\hline No & \multicolumn{1}{|c|}{ Properties } & Test methods \\
\hline 1 & Flow & ASTM C1437-07 [5] \\
\hline 2 & Expansion of fresh grout mortar & ASTM C940-16 [6] \\
\hline 3 & Bleeding & ASTM C940-16 \\
\hline 4 & Compressive strength & ASTM C349-14 [7] \\
\hline 5 & Length change of hardened grout mortar & ASTM C157-14 [8] \\
\hline
\end{tabular}

For the expansion and bleeding of fresh grouts, the cement suspension was poured into a $1000 \mathrm{~mL}$ graduated cylinder until the volume of the suspension reached $800 \pm 10 \mathrm{~mL}$. The bleeding was measured at 15 minutes intervals for the first 60 minutes, and then bleeding values were read every 1 hour until the suspension was stable. 


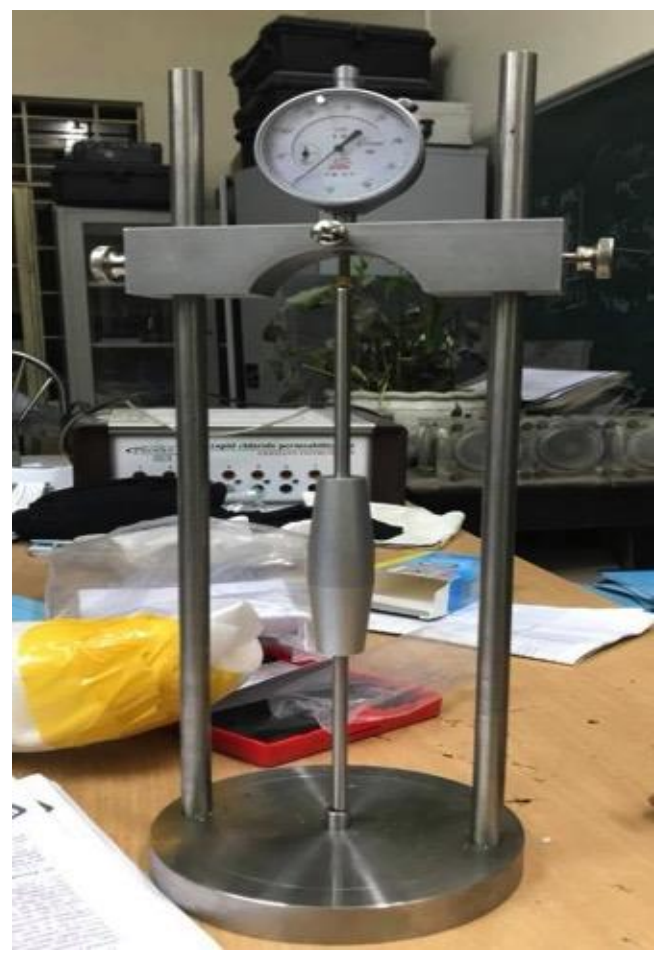

Figure 2. Length comparator for length change test of hardened grout.

For this purpose, prism specimens measuring $40 \times 40 \times 160 \mathrm{~mm}$ were prepared for both compressive and flexural strengths for each grout mortar according to ASTM C349. The flexural and compressive strength tests were carried out at the ages of 1, 3, 7 and 28 days. For each grout mortar, the compressive strength was determined by taking the average of six test results, whereas the flexural strength was determined as an average of three samples.

On the other hand, the prism specimens of $25 \times 25 \times 285 \mathrm{~mm}$ were used for testing of length change of hardened grout mortar (drying shrinkage).

\section{EXPERIMENTAL RESULTS}

\subsection{Flowability test of the grouts}

The flow results of tested grout mixtures are detailed in the table 5.

The obtained flow diameters were in range of 21 to $27 \mathrm{~cm}$. The lowest flow diameter was measured for the grout CT1, followed by the CT2 while the CT3 had the highest value. This trend can be explained by the highest mass of HRWR using in the CT3 mixture.

Table 5. Results on flow tests of the grout mixture.

\begin{tabular}{|c|c|c|c|c|}
\hline Mixte & $\begin{array}{c}\text { First time } \\
(\mathbf{c m})\end{array}$ & $\begin{array}{c}\text { Second time } \\
(\mathbf{c m})\end{array}$ & $\begin{array}{c}\text { Third time } \\
(\mathbf{c m})\end{array}$ & $\begin{array}{c}\text { Average } \\
(\mathbf{c m})\end{array}$ \\
\hline CT1 & 22 & 21 & 22 & 21.7 \\
\hline CT2 & 24 & 24 & 25 & 24.3 \\
\hline CT3 & 26 & 26 & 27 & 26.3 \\
\hline
\end{tabular}

For all of grout mixtures, the HRWR dosage had achieved the target flow meeting the requirement of the vietnamese standard TCVN 9204:2012 [9] (over $20 \mathrm{~cm}$ ). 


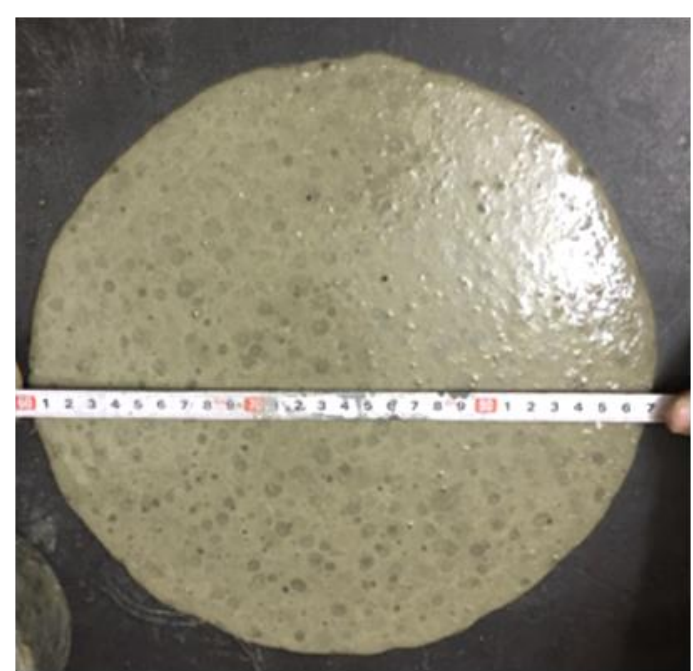

Figure 3. Flow test.

\subsection{Expansion and bleeding of the fresh grout}

Bleeding is a phenomenon in which water is squeezed out from pores between cement particles into the ground. Bleeding has some consequences such as reducing the mobility and pumpability of the grout. Lambardi [10] stated that a grout is considered stable when the final bleeding is less than $5 \%$ after $120 \mathrm{~min}$.

The visual inspection of all tested mortar mixtures showed no evidence of bleeding or segregation. For the control sample (no expansive agent) had been obsereved a soft shrinkage $(6 \%)$ and a water separation phenomenon.

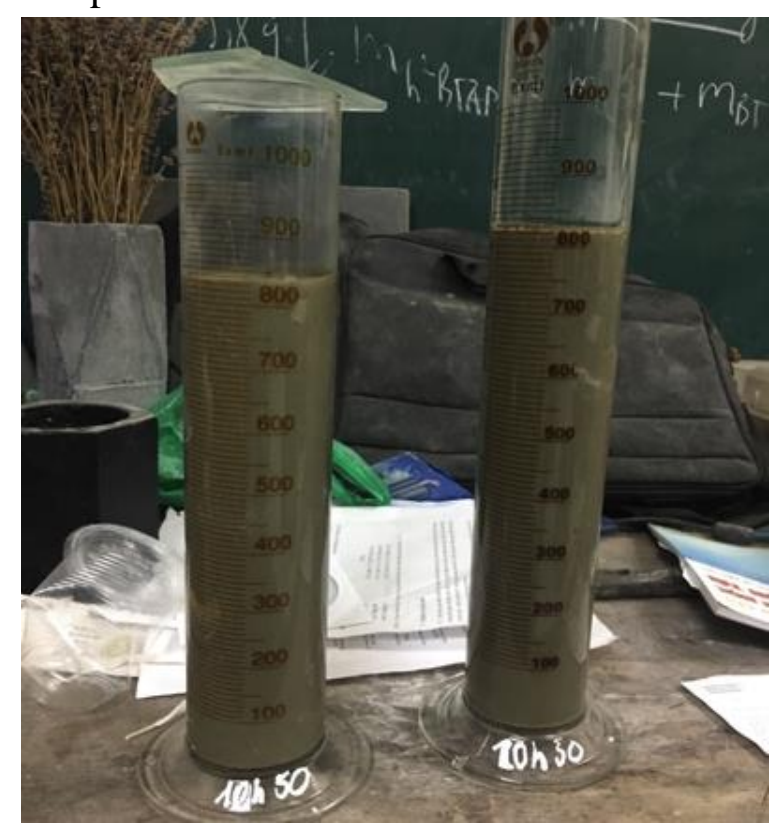

Figure 4. Test of the expansion and bleeding of fresh grout.

\subsection{Compressive and flexural strength of the grout}

The results of the compressive and flexural strength for the studied mortars are summarized in Table 6 and showed continuous increase with age, as shown in Figure 5 and 6 , respectively. Each test result is the average of 6 experimental samples. 
Transport and Communications Science Journal, Vol. 72, Issue 4 (05/2021), 477-485

Table 6. Compressive and flexural strengths of tested grouts.

\begin{tabular}{|c|c|c|c|c|c|c|c|c|}
\hline \multirow{2}{*}{ Mixtes } & \multicolumn{4}{|c|}{ Compressive strength (MPa) } & \multicolumn{4}{c|}{ Flexural strength (MPa) } \\
\cline { 2 - 9 } & 1 day & 3 days & 7 days & 28 days & 1 day & 3 days & 7 days & 28 days \\
\hline CT1 & 25.3 & 38.5 & 51.4 & 61.3 & 5.1 & 6.6 & 8.0 & 8.8 \\
\hline CT2 & 31.2 & 45.3 & 55.8 & 67.7 & 5.9 & 7.2 & 8.4 & 9.3 \\
\hline CT3 & 35.7 & 52.6 & 61.6 & 71.6 & 6.2 & 7.8 & 9.1 & 9.5 \\
\hline
\end{tabular}

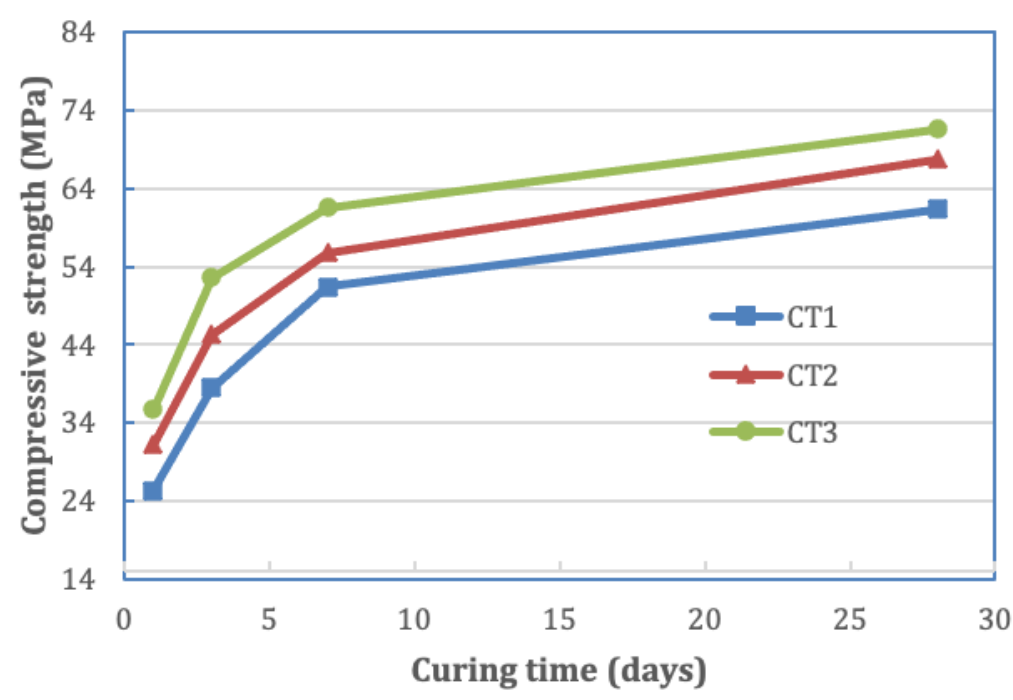

Figure 5. Development of compressive strength of the grout mixtures over curing time.

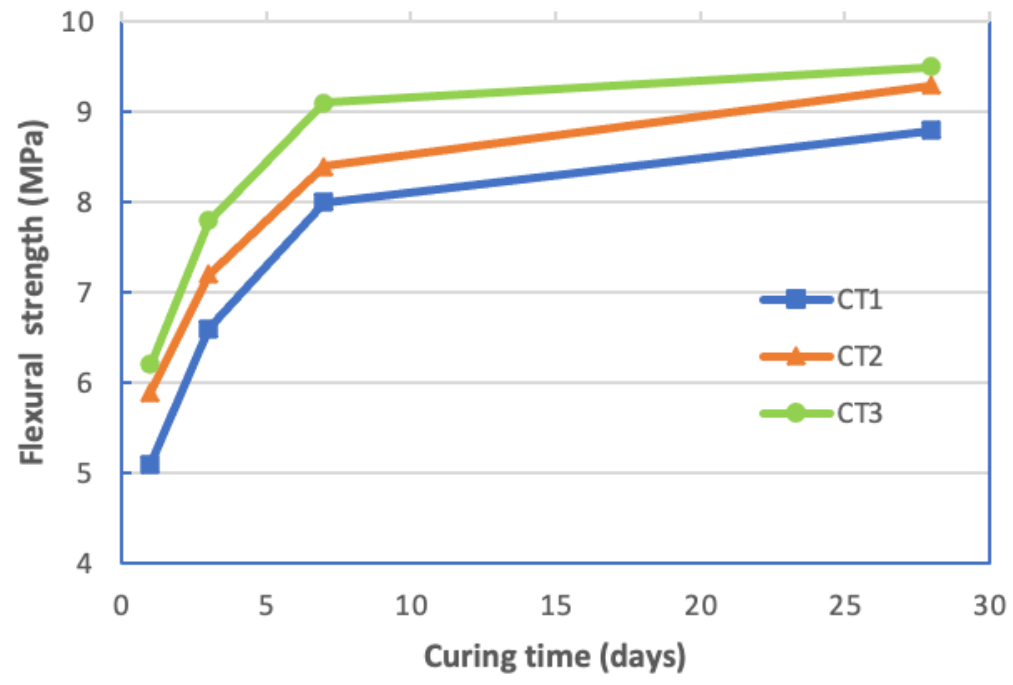

Figure 6. Development of flexural strength of the grout mixtures over curing time.

At all ages, the compressive strength of the CT1 and CT2 mortars were lower than that of the CT3. The higher compressive strength was reported for the CT3, followed by the CT2, and then the CT1.

At the early curing period, the mixture CT2 and CT3 have compressive strengths after 
one day up to over $30 \mathrm{MPa}$, meeting the requirement of strength for the early construction. After three days of curing, the mixture CT3 exhibited significantly higher compressive strength than that of the CT1 and CT2. The reductions in compressive strength values for the CT1 and CT2 compared to the CT3 were $27 \%$ and $14 \%$, respectively. In the same way, at 28 days of curing, the reductions in compressive strength values of CT1 and CT2 compared to the CT3 were $15 \%$ and $5 \%$, respectively.

On the other hand, the short-term strength (at seven days) of CT3 can be attributed a significantly great compressive strength up to more than $60 \mathrm{Mpa}$. After 28 days of curing, that mixture had slightly greater increase in the compressive strength $(14 \%)$ compared to the 7 days strength.

In summary, all of the grout mortars had 28-day compressive strength values from 60 to $71 \mathrm{MPa}$, fulfilling the requirements for the high strength grout.

The evolution of the flexural strength (Figure 6) with time was similar to that observed in the case of the compressive strength. It is observed that the increase of ration W/B from 0.29 to 0.33 in CT1 reduced the flexural strength values of CT1 compared to the CT3 by about $17 \%$ and $7 \%$ at 1 and 28 days, respectively. At the same ages, the decrease of ration W/C from 0.29 to 0.31 in CT2 resulted in $5 \%$ and $2 \%$ reductions in the flexural strength values, respectively.

\subsection{Length changes of hardened grout (drying shrinkage)}

The dry shrinkage test results of CT3 mixte and control sample (without expansive agent) are shown in figure 7 . Each result is the average of six test samples.

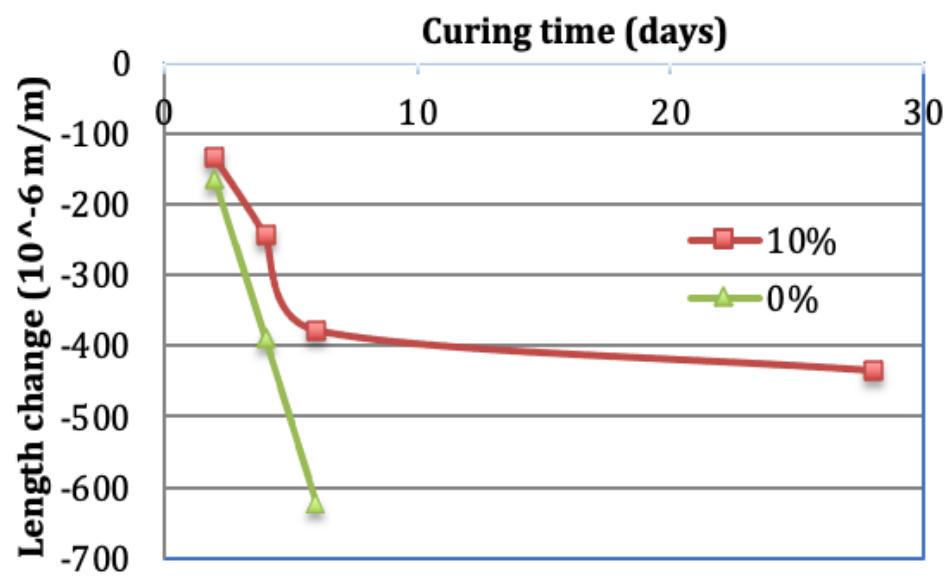

Figure 7. Length change of hardened mortar in comparaison with the one day of the CT3 and the control mixte (no expansive agent).

Experimental results show that when using a CSA based expansive additive with a proportion of $10 \%$, the dry shrinkage of the grout mortar is significantly reduced, $32 \%$ compared to the control sample. Thus it is possible to use the expansive agent with the dosage recommended by the manufacturer to meet the non-shrinkage requirement of a grout mortar.

\section{CONCLUSION}

The main purpose of this paper was to create some grout mixtures with minimized values of bleeding, appropriate flowability, high compressive strength, and in-range drying shrinkage for a high performance grout. This aim was achieved by using a polycarboxylate 
superplasticizer and a CSA expansive agent.

This study demonstrates that it is possible to successfully using proactive materials to produce high strength non-shrink grouts. It is to highlight that the 28 day compressive strength can be achieved up to greater than $60 \mathrm{MPa}$ while maintaining the Standard specifications for the grout mortar in terms of flowability, fresh expansion, bleeding, and dry shrinkage. The products can be produced and used for the real construction applications.

\section{REFERENCES}

[1]. M. R. Azadia, A. Taghichianb, A. Taheric, Optimization of cement-based grouts using chemical additives, Journal of Rock Mechanics and Geotechnical Engineering, 9 (2017) 623-637. https://doi.org/10.1016/j.jrmge.2016.11.013

[2]. T. B. Nguyen, B. V. Tran, Research on manufacturing high strength self-levelling grout with ultra thin polypropylene fiber, The $8^{\text {th }}$ Conference for Young Researchers, Vietnam Institute for Buildings Science and Technology, (2011). (In Vietnamese).

[3]. Q. V. Vu, Experimental research results on the production of non-shrink grout for repair of Ta Duong dike, Bac Ninh province, (2012). (In Vietnamese) http://www.vncold.vn/Web/Content.aspx?distid=2907

[4]. ASTM C33-08, Standard Specification for Concrete Aggregates, (2008). https://www.astm.org/DATABASE.CART/HISTORICAL/C33C33M-08.htm

[5]. ASTM C1437-07, Standard Test Method for Flow of Hydraulic Cement Mortar, (2007). https://www.astm.org/DATABASE.CART/HISTORICAL/C1437-15.htm

[6]. ASTM C940-16, Standard Test Method for Expansion and Bleeding of Freshly Mixed Grouts for Preplaced-Aggregate Concrete in the Laboratory, (2016). https://www.astm.org/Standards/C940

[7]. ASTM C349-14, Standard Test Method for Compressive Strength of Hydraulic-Cement Mortars (Using Portions of Prisms Broken in Flexure), (2014). https://www.astm.org/DATABASE.CART/HISTORICAL/C349-14.htm

[8]. ASTM C157-14, Standard Test Method for Length Change of Hardened Hydraulic-Cement, Mortar, and Concrete, (2014). https://www.astm.org/Standards/C157

[9]. TCVN 9204:2012, Packaged dry, hydraulic-cement grout (non-shrink), (2012). (In Vietnamese). https://vanbanphapluat.co/tcvn-9204-2012-vua-xi-mang-kho-tron-san-khong-co

[10]. G. Lambardi, The role of cohesion in cement grouting of rock, Proceedings of the 15th International Congress on Large Dams, (1985), 235-260. 